\title{
Upah Minimum, Skala Upah dan Produktifitas Kerja
}

\author{
Tuwinanto ${ }^{(1)}$ \\ Dedi Rianto Rahadi ${ }^{(2)}$ \\ Presiden University ${ }^{(1)}$ \\ tuwinanto@student.president.ac.id ${ }^{(1)}$
}

\begin{abstract}
The minimum wage in Indonesia is one that is often discussed in the industrial world, this is because there are still some companies that implement a wage system that does not include a wage scale instrument, one of which is the period of work. So that it causes disharmony between old workers and new workers and can make internal communication not run smoothly.
\end{abstract}

Keywords: Wage scale structure; and Minimum Wage

\begin{abstract}
ABSTRAK
Upah minimum diIndonesia menjadi salah satu yang sering dibicarakan didunia industry, hal ini dikarenakan masih ada beberapa perusahaan yang melakukan system pengupahan tidak memasukan instrument skala upah salah satunya masa kerja. Sehingga menimbulkan ketidak harmonisan antara pekerja lama dengan pekerja baru dan dapat membuat komunikasi internal menjadi tidak berjalan lancar.
\end{abstract}

Kata Kunci : Struktur skala Upah; dan Upah Minimum

\section{PENDAHULUAN}

Setiap negara mempunya perbedaan antara negara satu dengan yang lainnya, karena ada perbedaan budaya, sumber daya dan pendapatan perkapita, Menurut para ahli pengupahan biasanya didasarkan kepada tiga fungsi gaji menurut (Payaman Simanjuntak, 1998 : 129), yaitu: Pertama kehidupan yang layak bagi pekerja dan keluarga, kedua nilai seimbang antara hasil kerja dengan upah dan 3. Penambahan insentif untuk medorong peningkatan produktifitas.

Negara asia yang menjadi sasaran investor asing utnuk menanamkan modalnya adalah Negara Indonesia. Perkembangan dunia teknologi dan informasi mendorong industrialisasi baik manufactur dan digital yang semakin berkembang pesat dan hampir masuk keseluruh sendi sendi kehidupan sosial dan budaya serta Gaya hidup masyarakat (Darma dan Noviana, 2020; Priskila dan Darma, 2020; Shavitri dan Darma, 2020; Sudiwedani dan Darma, 2020; Dewi dan Darma, 2019; Narolita dan Darma, 2020; Juzer dan Darma, 2019; Asri dan Darma, 2020; Krismajayanti dan Darma, 2020; Bali dan Darma, 2019; Desyanta dan Darma, 2020; Utomo dan Darma, 2020; Handayani dan Darma, 2021; Yong dan Darma, 2020; Rivaldo et al., 
2021). Kebutuhan Akan tenaga kerja professional yang sudah mempunyai pengalaman akan bisa bertahan dibandingkan tenaga kerja pemula atau fresh Graduated.

Persoalan Pengupahan yang timbul dari dampak industrialisasi ini Akan terus berlarut jika tidak ditemukan formulasi untuk memberikan besaran nilai upah yang diterima oleh karyawan, yang tentunya didasari pada asas keadilan dan transparansi. Gejolak demonstrasi penolakan Upah menjadikan kondisi ini akan menciptakan efek yang kurang bagus untuk iklim Investasi diIndonesia.maka dari itu diperlukannya metode Skala Upah dan instrumentinstrumen yang berkaitan dengan Kebutuhan Hidup Layak (KHL).

\section{METODE PENELITIAN}

Prosedur dalam riset ini memakai tata cara Riset kualitatif. yang maksudnya Tata cara kualitatif merupakan riset yang digunakan buat mempelajari pada keadaan objek alamiah, dimana periset ialah instrumen kunci (Sugiyono, 2005).

Lokasi pengambilan sample adalah kawasan Industri MM2100 di Kabupaten Bekasi. Dengan memberikan beberapa pertanyaan kepada karyawan yang bekerja di kawasan tersebut. Berikut beberapa pertanyaan yang dilakukan dengan teknik wawancara secara Langsung.

1. Apakah di Perusahaan Anda sudah menjalankan pengupahan sesuai Undang undang?

2. Apakah Upah dibawah standar pemerintah?

3. Apakah perusahaan sudah memasukan instrument skala upah dalam proses perhitungan Upah?

\section{HASIL DAN PEMBAHASAN}

Setiap Perusahaan yang berada diwilayah hukum negara republik Indonesia semua mempunyai dasar peraturan tentang ketenaga kerjaan yang sama yang membedaka hanya kebijakan perusahaan, Semua peraturan yang berkaitan dengan jaminan kesehatan, Gaji pokok, tunjangan, jam kerja lembur semua sudah diatur bahkan sampai pada perhitungan Uang pesangon pada saat Pensiun.

Pada praktek dilapangan masih ada ditemukan beberapa perusahaan yang masih belum memasukan instrument masa kerja untuk dijadikan tambahan atas upah buruh yang sudah bekerja sekian lama sebagai nilai tambah atas pengabdian selama dibekerja.

Dari hasil wawancara dihasilkan data sebagai berikut:

1. Apakah di Perusahaan Anda sudah menjalankan pengupahan sesuai UndangUndang? 


\section{Upah sudah sesuai Undang-Undang ?}

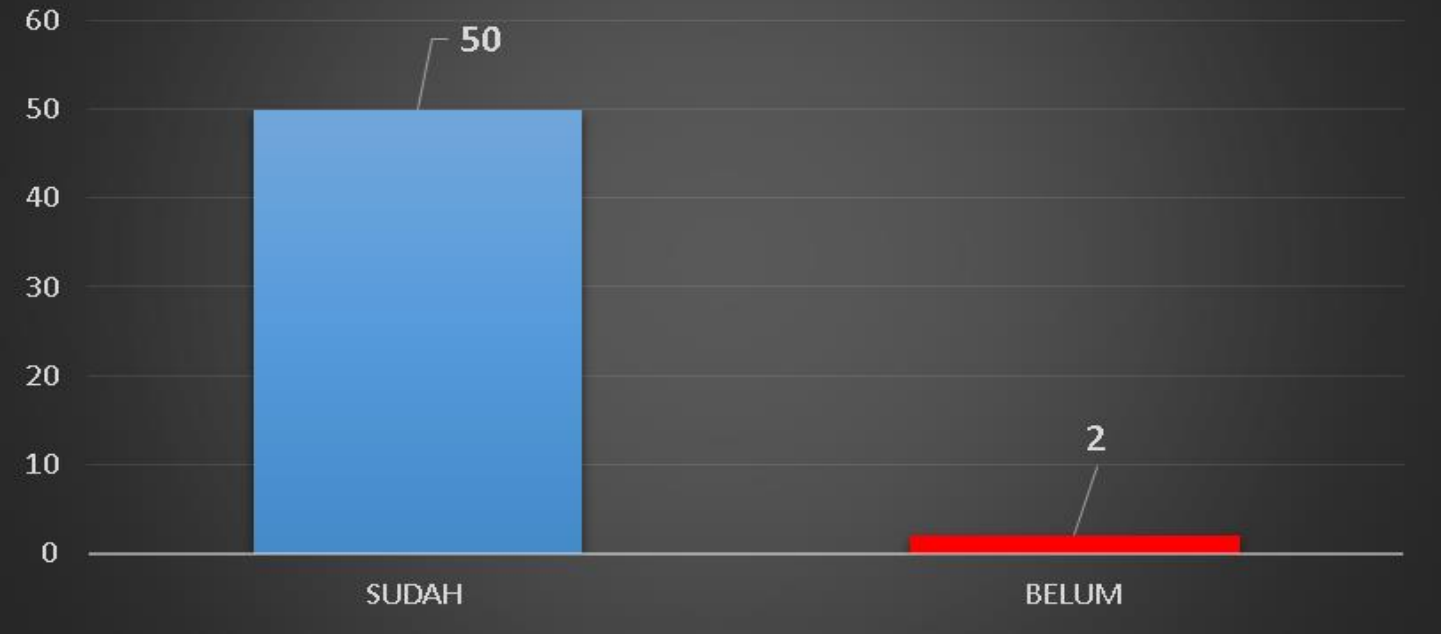

Gambar 1. Kesesuaian dengan Undang-undang

Dari hasil sampling dengan total narasumber sebanyak 52 karyawan dengan perusahaan yang berbeda, Memberikan data hampir semua perusahaan sudah sesuai dengan undangundang tentang pengupahan. Namun masih ada sedikt perusahaan yang masih belum sesuai dengan peraturan.

2. Apakah upah dibawah standar pemerintah?

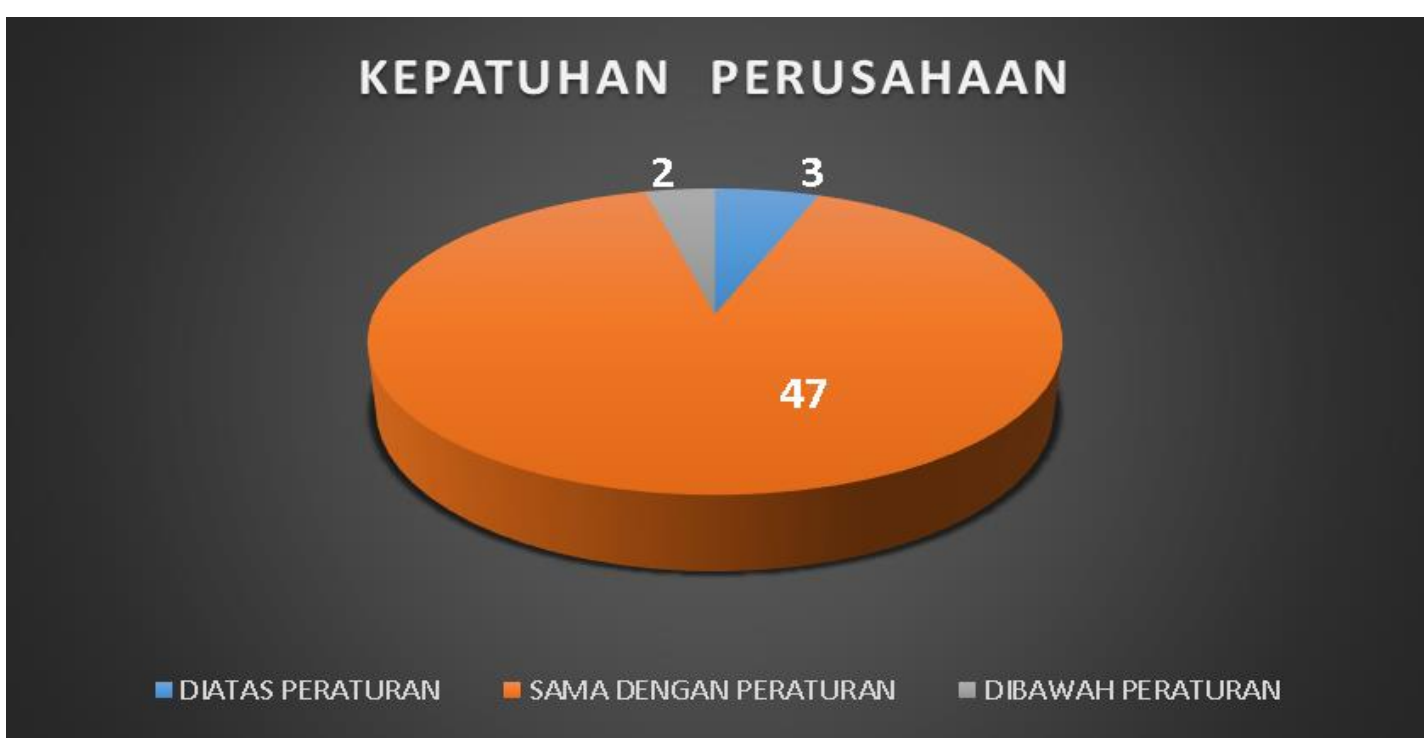

Gambar 2. Besaran Upah 
3. Apakah perusahaan sudah memasukan instrument skala upah dalam proses perhitungan Upah?

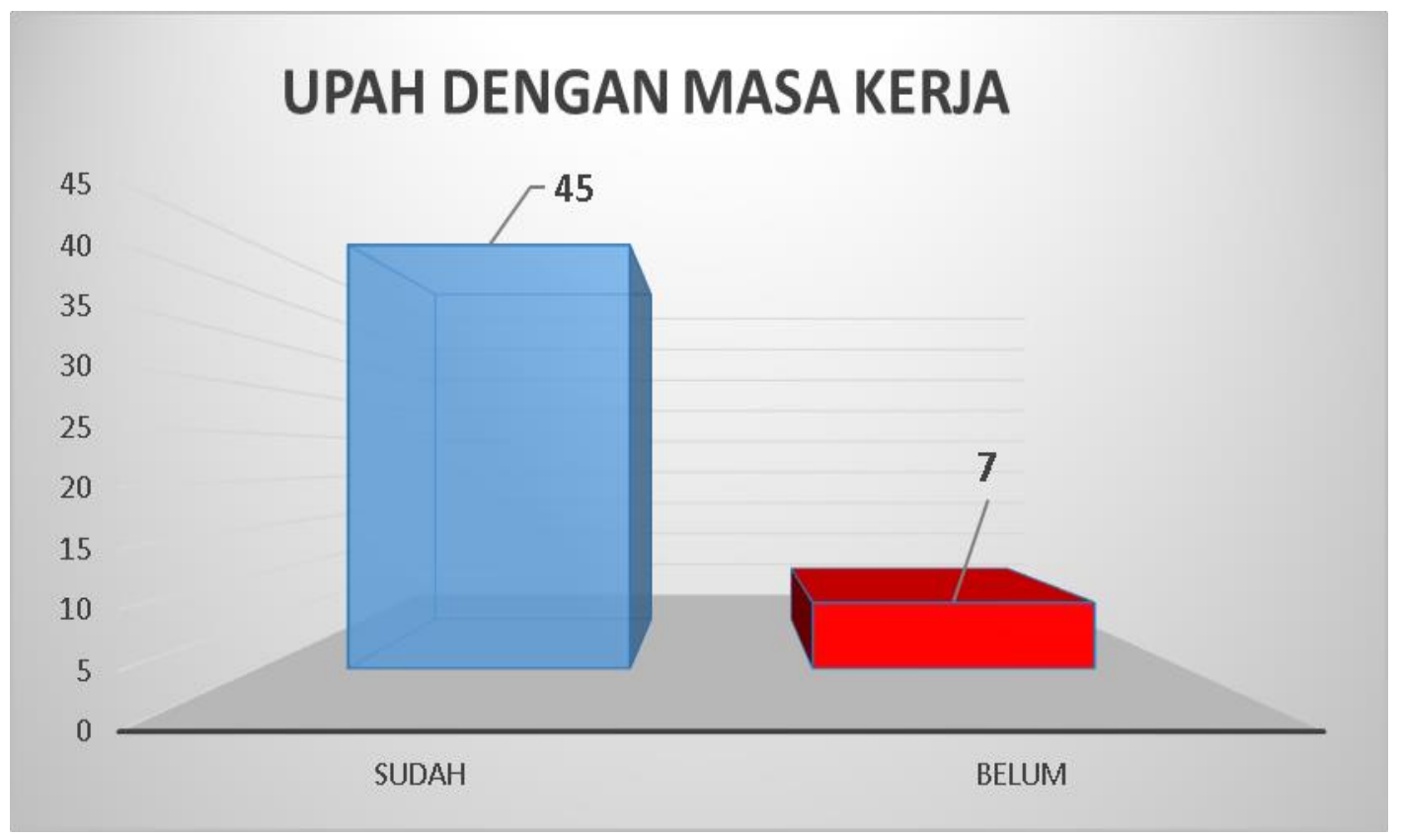

Gambar 3. Perusahaan yang mengikutkan instrument masa kerja

Sebenarnya setiap perusahaan sudah menyiapkan anggaran produksi yang disiapkan oleh para pemilik merek internasional sebesar $25 \%$ dengan alokasi dana untuk buruh hanya 1 $\%$ - $2 \%$ (Bhattacharjee and Roy, 2015). Sehingga dana yang begitu kecil ini membuat para manager perusahaan melakukan pengetatan anggaran untuk karyawan.

Dengan kondisi diatas maka sudah selayaknya pemerintah dengan kementrian Perindustrian dan jajaran pemerintah provinsi, kabupaten melakukan terobosan guna mengurangi dampak dari ketidakpastian hukum tentang penetapan upah dengan wajib memasukkan cara skala Upah (Mukherjee, 2015).

Selain survei harga bahan pokok, ada 2 komponen lagi yang menentukan UMK yaitu inflasi dan pertumbuhan ekonomi. Kenaikan UMK tahun 2020 Pandemic covid 19 menjadi alasan utama pengusaha menjadi keberatan sehingga banyak dikeluhkan kalangan pengusaha yang keberatan dengan hal itu. Para pengusaha merasa banyak beban yang harus dikeluarkan untuk biaya produksi, peningkatkan kesehatan karyawan, biaya tambahan rapid tes dan lain lain, sedangkan inflasi naik dan pertumbuhan ekonomi di Indonesia menurun.

Konflik yang berkepanjangan ini membuat iklim usaha dan investasi menjadi tidak kondusif, sehingga banyak pengusaha mengalihkan lokasi usahanya ke daerah yang masih relative terjangkau UMK nya seperti Jawa tengah. 
Sesudah Penetapan UMP timbul masalah baru yaitu kecemburuan social antara karyawan yang sudah mempunyai masa kerja dengan karyawan yang masih baru. Hal ini disebabkan oleh perusahaan masih banyak yang belum menerapkan skema Skala Upah dengan memperhitungkan Grade, Posisi, Masa kerja, Pendidikan dan Skill. Sehingga perhitungan upah lebih obyektif dan tidak menimbulkan konflik di internal perusahaan antara karyawan baru dengan karyawan lama.

Masa kerja merupakan jangka waktu ataupun lamanya seorang bekerja pada sesuatu lembaga, kantor serta sebagainya (Koesindratmono, 2011). Skala upah perlu diberlakukan disetiap perusahaan untuk menghindari tingkat kecemburuan social antar karyawan yang baru dengan yang lama, yang mengakibatkan menurunnya produktifitas kerja karyawan. Menurut para ahli Produktivitas diartikan sebagai kemampuan memperoleh imbalan yang sebesarbesarnya dari sarana dan prasarana dengan menghasilkan barang dan jasa yang optimal. Sehingga produktifitas sangat penting dalam masalah perusahaan, semakin kecil produktifitasnya semakin besar kemungkinan perusahaan tidak akan bisa bersaing dengan kompetitornya. Dijelaskan oleh para ahli Menurut Bambang Kusiryanto (2009:1) yang menjelaskan bahwa Produktivitas itu kalkulasi antara output dengan total biaya, baik biaya wajib ataupun biaya tambahan.

Pemberian upah juga harus memperhitungkan kinerja karyawan sehingga bisa tepat dan efektif, Sedangkan Menurut Heidjrachman dan Husnan (2005:206), menyatakan bahwa kesejahteraan adalah suatu kondisi aman. Jadi rasa aman juga menjadikan tingkat kinerja pegawai meningkat. Maka dari itu arti lain dari Upah ialah bayaran financial (uang) secara langsung yang dibayarkan kepada pekerja berdasarkan total jam kerja, jumlah barang yang dihasilkan atau banyaknya pelayanan yang diberikan. (Veithzal Rivai, 2009:758; Rusmahadewi dan Darma, 2018; Handayani dan Darma, 2018; Kolo dan Darma, 2020).

Dengan demikian bahwa terdapat hubungan sangat erat antara besaran upah atau tingkat kesejahteraan dengan semangat kerja karyawan, sehingga dapat diambil kesimpulan yaitu semakin besar gaji yang diterima oleh pekerja, maka dapat meningkatkan kinerja pekerja itu sendiri. Dalam Hubungannya antara upah serta Kinerja (Gibson, 1996) melaporkan kalau salah satu yang pengaruhi kinerja orang yang sangat kokoh merupakan sistem balas jasa ataupun upah organisasi ataupun industri. Jika pengupahan tidak dilakukan secara proporsional maka akan timbul penurunan motivasi pekerja Dalam perihal ini upah jadi aspek sangat bernilai, karenanya upah bakal sangati efisien andaikan bersinggungan dengan kinerja secara benar (Noe, 2000; Widiatmika dan Darma, 2018; Wulandari dan Darma, 2020; Wardana dan Darma, 2020). Besaran gaji akan membuat kinerja dan rasa mencintai karyawan terhadap perusahaan 
semakin tinggi, Seperti dijelaskan secara detail oleh Dessler (1997) yang menyatakan bahwa gaji adalah menjadi faktor penting yang bisa meningkatkan semangat seseorang untuk bekerja. Dari sisi lain, sifat kepuasan berhubungan sangat dekat sekali dengan instrumen yang menumbuhkan atau memulai perilaku (Gitosoedarmo \& Sudita, 1997; Wiandari dan Darma, 2017; Darma et al., 2019; Murti dan Darma, 2021).

Perusahaan yang belum menetapkan skala upah dalam pemberian Upah Akan menimbulkan kecemburuan social antar sesame pekerja yang akan berakibat pada menurunnya kinerja sehingga bisa menurunkan produktifitas pekerja. Instrumen dalam penghitungan skala upah juga harus memperhatikan aspek aspek social seperti tingkat masa kerja dan pengalaman kerja.

\section{PENUTUP}

Setiap Perusahaan sudah menjadi kewajiban untuk memperhitungkan intrumen skala upah baik dari sisi tingkat pekerjaan,tanggung jawab maupun masa kerja,sehingga tercipta kondisi hubungan antar pekerja yang lama dengan yang barutidak terjadi kecemburuan social, serta dapat meningkatkan produktifitas pekerja.

Pimpinan perusahaan harus melakukan kajian tentang instrument apa yang harus dijadikan dasar perhitungan skala upah bagi pekerja, contohnya seperti: masa kerja, Job description, Tanggung jawab dan lain lain.Agar memberikan penilaian secara obyektif dan lebih bisa diterima oleh semua karyawan.Perusahaan wajib membuat struktur skala upah dengan mengacu Peraturan menteri ketenagakerjaan. 


\section{DAFTAR PUSTAKA}

Asri, A. A. S. M. A. N., \& Darma, G. S. (2020). Revealing the digital leadership spurs in 4.0 industrial revolution. International Journal of Business, Economics \& Management, 3(1), 93-100. https://doi.org/10.31295/ijbem.v3n1.135.

Bali, I.N.A.P., and Darma, G.S. (2019). Menguji Kesiapan Pengelolaan Desa Berbasis Manajemen Modern Guna Menghadapi Era Revolusi Industri 4.0, Jurnal Manajemen \& Bisnis, 16 (2): 1-13.

Darma, G.S., \& Noviana, I.P.T. (2020). Exploring Digital Marketing Strategies during the New Normal Era in Enhancing the Use of Digital Payment. Jurnal Mantik, 4(3), 2257-2262. https://doi.org/10.35335/mantik.Vol4.2020.1084.pp2257-2262.

Darma, G.S., Wicaksono, K., Sanica, I.G., and Abiyasa, A.P. (2019). Faktor Kompensasi dan Strategi Gojek Dalam Meningkatkan Kepuasan Kerja Para Driver, JURNAL ILMIAH MANAJEMEN BISNIS DAN INOVASI UNIVERSITAS SAM RATULANGI, 6 (3): 232-244.

Desler. (1997). Humman Resurces Management. New Jersey.

Desyanta, I. G. P. R., \& Darma, G. S. (2020). Development of Business Model Digital Fraction Property Investment. Jurnal Entrepreneur dan Entrepreneurship, 9(2), 67-78. https://doi.org/10.37715/jee.v9i2.1343

Dewi, M.V.K., and Darma, G.S. (2019). The Role of Marketing \& Competitive Intelligence In Industrial Revolution 4.0, Jurnal Manajemen \& Bisnis, 16 (1): 1-12.

Gibson, J. L. (1996). Organisasi: Perilaku, Struktur, Proses.

Gitosudarmo, I. d. ( 1997). Perilaku Keorganisasian.Yogyakarta: BPFE.

Handayani, L.P.D.S., \& Darma, G. S. (2021). Pengaruh Kebijakan Pemeriksaan, Kebijakan Akses Informasi Keuangan dan Forensik Digital terhadap Kualitas Pemeriksaan Pajak. Syntax Literate; Jurnal Ilmiah Indonesia, 6(3), 1260-1272.

http://dx.doi.org/10.36418/syntax-literate.v6i3.1142

Handayani, K.A.T., and Darma, G.S. (2018). Firm Size, Business Risk, Asset Structure, Profitability, and Capital Structure, Jurnal Manajemen \& Bisnis, 15 (2): 48-57.

Heidjrachaman dan Husna, S. (2005). Manajemen Personalia. Yogyakarta: BPFE. Juzer, J., and Darma, G.S. (2019). Strategic Supply Chain Management in the Era of Industry Revolution 4.0 : A Study of Textile Industry in Bali, Jurnal Manajemen Bisnis, 16 (3): $1-16$. 
Krismajayanti, N.P.A., \& Darma, G. S. (2020). Challenges and Strategies to Encourage Women to be Entrepreneurs in The Industrial Revolution Era. Review of Management, Accounting, and Business Studies, 1(1), 12-20.

Koesindratmono, F. S. (2011). Hubungan masa kerja dengan Upah.

Kusriyanto, B. (1991). Meningkatkan Produktivitas Karyawan. Jakarta:. PT. Pustaka Binaman Presindo.

Kolo, S.M., and Darma, G.S. (2020). Faktor-Faktor Terpenting Yang Mempengaruhi Kepuasan dan Loyalitas Pelanggan Pengguna Jaringan 4G di Denpasar, Jurnal Manajemen Bisnis, 17 (1): 57-74.

Mukherjee, P. R. (2015). Electrochimica Acta. Improved catalysis of room temperature synthesized $\mathrm{Pd}-\mathrm{Cu}$ alloy nanoparticles for anodic oxidation of ethanol in alkaline media. 154.

Murti, K.G.K., \& Darma, G. S. (2021). Jalan Terjal Online Travel Platform Hadapi Pandemi. Syntax Literate; Jurnal Ilmiah Indonesia, 6(5), 2280-2296. http://dx.doi.org/10.36418/syntax-literate.v6i5.2703

Narolita, D., and Darma, G.S. (2020). Prodia: disruption in clinical laboratory service system, International research journal of management, IT and social sciences, 7 (1): 9-18.

Noe. (2000). Humman Resources Managment.

Priskila, S., \& Darma, G.S. (2020). Employee Perception of Brand Value in the Jewelry Industry. Journal of Economics, Business, \& Accountancy Ventura, 23 (2). http://dx.doi.org/10.14414/jebav.v23i2.2281.

Rivai, V (2009). Manajemen Sumber Daya Manusia untuk Perusahaan. Jakarta: Rajagrafindo Persada.

Rivaldo, I. M. G., Lestari, N.P.N.E., \& Darma, G.S., \& Gorda, A.A.N.E.S. (2021). Integrating The Credit Lending Strategies of Multi-Purpose Cooperatives (a Case Study at KSU Dauh Ayu in Denpasar). Jurnal Mantik, 4(4), 2318-2324. https://doi.org/10.35335/mantik.Vol4.2021.1138.pp2318-2324

Rusmahadewi, I.A., and Darma, G.S. (2018). Team Engagement and Performance Management (A Study of Banking Industry), Jurnal Manajemen \& Bisnis, 15 (3): 3850.

Shavitri, L.P.D., \& Darma, G.S. (2020). Pengaruh Implementasi Kebijakan Pemeriksaan dan Forensik Digital terhadap Kualitas Pemeriksaan dan Keberhasilan Penerimaan Pajak. E-Jurnal Akuntansi, 30(10), 2682 - 2697. https://doi.org/10.24843/EJA.2020.v30.i10.p19 
Sudiwedani, A., \& Darma, G.S. (2020). Analysis of the effect of knowledge, attitude, and skill related to the preparation of doctors in facing industrial revolution 4.0, Bali Medical Journal, 9(2), 524-530. https://dx.doi.org/10.15562/bmj.v9i2.1895.

Simanjuntak., P. J. (2000). Pengantar Ekonomi Sumber Daya Manusia - Edisi Kedua. Buku 1 Edisi 4. Lembaga Penerbit- FE UI.

Sugiyono. (2005). Memahami Penelitian Kualitatif. Bandung: CV. Alfabeta.

Utomo, I.G.W., and Darma, G.S. (2020). Measuring optimization of digital military programs: an innovation of information and communication systems in industrial digitalization 4.0, International research journal of engineering, IT \& scientific research, 6(2), 3946.

Wiandari, I.A.A., and Darma, G.S. (2017). Kepemimpinan, Total Quality Management, Perilaku Produktif Karyawan, Kinerja Karyawan dan Kinerja Perusahaan, Jurnal Manajemen \& Bisnis, 14 (2): 61-78.

Widiatmika, P.H., and Darma, G.S. (2018). Good Corporate Governance, Job Motivation, Organization Culture Which Impact Company Financial Performance, Jurnal Manajemen \& Bisnis, 15 (3): 82-99.

Wulandari, N.L.P.T., \& Darma, G.S. (2020). Textile Industry Issue in Pandemic of Covid-19. PalArch's Journal of Archaeology of Egypt / Egyptology, 17(7), 8064-8074. Retrieved from https://archives.palarch.nl/index.php/jae/article/view/3526.

Wardana, I.M.A., \& Darma, G.S. (2020). Garment Industry Competitive Advantage Strategy During Covid-19 Pandemic. PalArch's Journal of Archaeology of Egypt / Egyptology, https://www.archives.palarch.nl/index.php/jae/article/view/2732.

Yong, I.D., \& Darma, G.S. (2020). Indikator Penentu Naik Turunnya Harga Saham pada Perusahaan High Deviden 20 Periode Tahun 2014-2019. Syntax Literate; Jurnal Ilmiah Indonesia, 5(12), 1591-1610. doi:10.36418/syntax-literate.v5i12.1907 